\title{
Physicalistic Reasoning in Management Science
}

\author{
T. GOSPODAREK* \\ Walbrzych High School of Management and Entrepreneurship \\ Wrocławska 10, Wałbrzych, Poland
}

\begin{abstract}
The main goal of this paper is to show a link between physicalistic reasoning and management problems, as well as to prove their usefulness for the quantization and computational support of decision-making under the conditions of uncertainty. The study lists a number of management-science topics juxtaposed with models derived from physics and formal descriptions of selected physical phenomena. The descriptions can be used in building models based on analogies with certain issues in management, especially related to the quantitative approach, where the definitions of measure are not well established. The most valuable contribution to management science derived from physical reasoning seems to be the introduction of a widely accepted definition of the managed system from an external and internal observer's viewpoint, and the definition of the state of the system at a given moment in time. The most promising results of the paper include the epistemological ordering, with an acceptable definition of the measure resulting from it. The physical approach offers a possibility of building an epistemological framework for management science, based on the logic of scientific discovery and combining similar results obtained from complementary disciplines, particularly psychology and social sciences.
\end{abstract}

PACS numbers: 89.65.Gh, 89.75.Fb, 89.90.+n

\section{Introduction}

In management science $^{\dagger}$, an essential element in the progress of knowledge is the ontological description or applicable functional model of social sciences [1-3]. The epistemology of management science is considerably deregulated, and the few attempts at ordering the existing situation have been rather unimpressive [4-6]. One of the main reasons for this situation is the low acceptance level of the application of description methods of the entity and the object of management that would be equivalent to the descriptions used in physics or chemistry, where studies of phenomena from an external observer's perspective allow to analyse the micro-macro interactions and to draw certain averages related to the micro state. The above derives from the archetype of a management process, which tends to be associated with the influence of people over people, whereas the physical description of the phenomenon leads to its over-reification, rather unacceptable in social sciences $[7,8]$. The classic philosophical

\footnotetext{
* corresponding author; e-mail: tgospo@op.pl

$\dagger$ The term, "Management science" is often understood as the quantitative methods and mathematical modeling in management theory, mainly related to operation research (JEL section C). But in this paper, it should be identified more generally, as a set of scientific problems related to business administration, organization development, micro and macro economics, classified by JEL sections C, D, E, M, O, P (see: http://www . aeaweb.org/ journal/jel_class_system.php ).
}

problem of demarcation in relation to management science is strongly diffused [9], and the applicability of the principles of the logic of scientific discovery, borrowed directly from physics, is not appropriate in management science [10]. A significant share of the behavioural aspects in management [11] means that, in principle, only very expressive semantic models may be considered appropriate analogies. Economic theories should be judged by three criteria: their congruence with reality, generality, and tractability [12]. This causes a very limited scope of applicability of any precise quantification of economic events related to the future. However, this does not exclude well-estimated forecasts and the use of certain quantified semantic models.

Within management science one can, however, determine measurable aspects concerning some interactions between an organization and its surroundings, for which the description of a model may be similar to that used in physics [13]. Management is always related to future events and understood as making certain decisions that lead to the occurrence of suitable processes according to the objective function [14] (the model of semantic interaction), which allows for the measurement of the micro state at the time $t_{1}$ and $t_{2}$. This leads to quantitative axiological evaluations but without accepting the philosophy of measurement, as is the case with natural sciences, it is impossible to use some well-matured formalisms direct, such as: the linear vector space [15], the game theory [16], the variation methods [17], etc.

For physicists, management and - more generally-social sciences may be a very interesting field to allocate rational reasoning by analogy and the use of formal models $[18,19]$. This conclusion results from the fact that 
in management the investigations are focused on objects with specific topologies, as well as interactions and development of systems over time. At the same time, there are significant limitations in the applicability of the analogies to natural sciences, a fact that is crucial to bear in mind before any data or inferences can be considered eligible for the conditions to be determined [20].

\section{Macroscopic characteristics of management}

In order to better define the areas for exploration of physical reasoning in management, let us identify some macroscopic properties of management. Management is always related to future events (from the nearest - at the operational level, to the distant — strategic ones); it is performed in relation to resources and organizations, involving changes in quantity, configuration, quality and usefulness; it is available for evaluation in the axiological sense ("good", "bad", "fair", etc.), which in turn requires a system of measurement scales and references; it is directed towards an optimization of a state of the objective, behaviour and interactions in accordance with the minimum or minimax principle in relation to the non-linear problems; it is based on decision making under the uncertainty arising from the fact that the consequences of those decisions relate to future periods of time and changes of the surroundings; and it is involved in an exchange of information or its processing, which releases the execution of the decision process.

Sometimes management can be evaluated quantitatively as a result of the implementation of a specific objective function or time-dependent equation of a state, it can be divided into logical steps or layers, using the reductionistic Cartesian approach for quantification purposes, it can be described in terms of the system (holistic) approach, from an external observer's viewpoint, and it leads to the desired strategic goals at the micro and macro level.

The following hypothesis may be proposed: there is no act of management without creating a mental model of the process in the form of its symbolic image (the representation of an abstract entity) suitable for transmission in a form understandable to the recipient of the information. Therefore, the axiological evaluation of management after a decision has been made, is based on the comparison of the states described by the model before and after the decision. The comparison must be based on the measurement of changes of model parameters or categorized entities, which requires the existence of a suitable measure. No full rationality of measurement in the quantization of social processes is possible because of the arbitrary choice of variables and parameters describing the changes in time. This is the major difference in comparison with the theory of physical measurement, where the objective is independent of the observer and the choice of coordinate systems. Moreover, a good physical experiment is possible to be repeated, which is not true of management. Here, one failed experiment may cause catastrophic consequences, even resulting in the destruction of the managed object.

In experimental mechanics and classic thermodynamics, time-dependent phenomena exhibit a continuous character, which allows to predict the consequences, at time intervals and with a good probability. However, management is divided into time ranges running in a discontinuous manner, and the consequences at a given time form the basis for a decision-making option in the next interval [21]. The optimization of such structures, displaying characteristics of the Markov process, is summarized in the Bellman equation [22]. It bears a strong analogy to the processes in natural science, and justifies the optimization of the operations research methodology in relation to the management of non-linear processes. It should be noted that action-oriented social sciences may also be a good field of the relations described above [23].

\section{Physicalistic definition of management}

The Stanford Encyclopedia of Philosophy states: Physicalism is the thesis that everything is physical, or as contemporary philosophers sometimes put it, that everything supervenes on, or is necessitated by, the physical. The general idea is that the nature of the actual world (i.e. the universe and everything in it) conforms to a certain condition, the condition of being physical. [24].

A lot of non-univocal definitions of management exist due to this epistemological disorder [4]. What does "management" mean? On the one hand, it can be recognized as an attempt to achieve a certain goal by an organization or group. On the other, it can be understood in terms of the optimization of certain processes, undoubtedly related to the conscious action of man enabling the achievement of objectives the shortest way; or the newsboy problem [25], where man is neither a subject nor object. One should not ignore the decision-making aspect extending to the future and taking place under the conditions of uncertainty [26]. In this case, the majority of issues relate to human intervention, but there are many exceptions to this rule, e.g. the decision making related to the automatic and intelligent control systems, such as aeroplane steering, cycle production, etc. [27]. Finally, management is also the issue of information processing, without which no management process is possible [13]. Information and knowledge management are subjects of several research disciplines.

An important element in describing the philosophy of management is measurement [18]. While measurable management always leads to estimable results, non-measurable management can only offer axiological evaluations - good or bad, but always strongly affected by subjective aspects. However, the effects of management always lead to a rational figure with a specific semantic interpretation (financial results, levels of market share, loss of personal information, etc.). This is related to the scale definition and measure construction for a given aspect [28]. 
Taking the above into consideration as a starting point for further discussion, one can suggest a physicalistic definition of management: Management is a set of interdisciplinary aspects ${ }^{\ddagger}$ related to decision-making under the conditions of uncertainty, optimizing the economic and social processes inside the organization and its surroundings, bringing the effects in any future period of time. In other words, management is always an act of creating a managed entity model in the form of its image in the future or its symbolic representation. If the above statement is accepted as accurate, then it influences the definition of a state of the managed object, the description of processes in time, the description of the permitted interactions, macro and micro parameters, etc., which is an interesting field for possible physical metaphors and analogies.

\section{Subject and object of management from a physical point of view}

The subject and object of management is an important problem in the philosophy of science, causing considerable epistemological controversy. Hence, research based on physical reasoning seems to be a good inspiration, allowing a precise and quasi-formal approach to the subject and object. The term "management" contains about 60 different aspects, including knowledge management, strategic management, etc. It does not seem possible to establish the clear subject and object, but rather a number of definitions for various cases in a more or less formal way.

In physics, one of the main subjects of research is a set of physical objects, either interacting with each other or not. Can we transfer the concept of state from physics to the system of resources of the organization on any basis? According to fundamentalistic epistemologists, there is no impediment to using this neoclassical approach, but not to treating the human being as an axiomatic foundation of the organization. The problem which is not acceptable for many researchers in the humanistic approach is reification, with its total elimination of the unique role of human beings and social aspects. That is exactly where physical reasoning differs from the social-science approach. From the standpoint of physical analogy to the system (many bodies interacting), the human is part of the base resources and his primary role in the organization is not relevant, even though he takes decisions which determine the state of the resources after a certain time. In the physicalistic approach, the state of a managed company at any given moment is determined by the properties of measurable resources, taken directly or through a numerical representation of its properties, e.g. usability, functionality, value, uniqueness, etc. From the

\footnotetext{
$\ddagger$ "Aspects" should be understood as all the problems classified by JEL in categories C, D, L, M, O, P.
}

standpoint of a social science researcher, human subjectivity and its role in the organization, and in particular in the non-measurable categories like happiness, prosperity, creativity and knowledge (identified in terms of human capital) are the most important aspects. The formal, physical approach to management may be adequate for defining the managed entity, understood as a collection of resources with specific characteristics and a general topology. Epistemologically, the inventor using physical reasoning remains in the position of a neoclassical quantitative reductionist, who needs to define and measure the state of the managed system at any given moment. Apart from the problem of the rationality of such an approach, it allows a consistent semi-formal approach to management in terms of transformation from state $A$ to state $B$ in a given space of resources (e.g. utility space in the Debreu sense) [29] and finding the objective function with a suitable numeric representation. Unfortunately, the true complexity of the problem and articulated statements concerning the future with the related boundaries, requires very careful research and estimations of possible uncertainty prior to detailed quantification.

Another element which is no less important for the philosophy of management is the isolated observer of the economic or social process. In mechanics, it is either an internal or external observer. There are no restrictions in using the same approach in management. It should, however, be made clear that there are limitations and potential consequences of demarcation. Statistical thermodynamics allows to isolate the motion or interaction components (e.g. helium atoms in closed volume $V$ ) and the description of the system by means of measurable macroscopic parameters such as pressure, temperature and volume. Reasoning along these lines gives good estimations of a micro state from the macro perspective in terms of thermodynamic ontology (a single helium atom in volume $V$ ) [30]. Trying to shift this model onto a set of organizations interacting economically with their surroundings, investigators encounter resistance from the opposite side of the reification and mechanistic approach to the description of management and organization, dealing with the interactions and internal relationships inside the set of resources of the organization, particularly those who do not understand the importance of the philosophy of science arising from the formal rules of the scientific method [10]. Unfortunately, they have a lot of reasons to support their views and only very well-conditioned models based on analogies may be accepted and practically verified.

An example of the macro approach and the role of the external observer in management is the approach of tax authorities. For them, it is completely unimportant what is happening inside the organization. The crucial thing is the countable result of the tax value within a given period of time and the compliance with the applicable business rules. The axiological assessment of management is simplified to the amount of added value generated by the macro system (a set of economic entities). It approxi- 
mates and legitimizes the physical reasoning related to a collection of black boxes (the organizations) in a given area, forming structures of resources, interacting with each other and with the surroundings [31]. Therefore, physical reasoning has a profound justification in macro management.

Can the approach to a management objective in the micro sense be approached similarly to the micro state in physics? In other words, can we speak of an internal state of the set of resources from the perspective of external macroeconomic data? It might seem that the answer is - definitely not. However, observing research results related to the system approach in organizations, it turns out that an explicit use of the model of the black box controlled by some external parameters may be accepted. Physical reasoning is a vital support for models of quantitative management, expressed in units of capital ${ }^{\S}$.

The above induces a discussion on the use of second-order cybernetics and physical models. The construction of self-organizing models of cybernetic systems steered by a finite set of steering parameters assumes that investigators are part of the system, and focuses on the importance of self-referentiality, self-organizing, the subject-object problem, etc. It is an example of self-adaptative management [47]. Also, steering systems with feedback are examples of second-order cybernetics. For physicists, it opens another very important problem: is it possible to describe the managed system by a finite set of current time variables? If some information derives from the past (late or feedback information), the system should also take into account some historical values. This assumption replaces simple differential equations describing the system with integral differential equations regarding time intervals in the $\left(t-t_{k}\right)$ form, where $k$ denotes the values of steering parameters in the $k$-th subinterval from the past [48]. For physicists, this problem is very interesting due to the definition of the state equation and possible simplifications and boundaries. Also, it is important to fix an acceptable border for time depth influence.

Another important part within the scope of physicists' interest are all types of interactions, from the mechanical to the specific thermodynamic intermolecular interactions. In management, however, we deal with the interactions of an organization with its surroundings, interactions between organizations and some intraorganizational relations. Adding the so-called informal relations, for which the concept of relational capital has no reference to any physical effects, further complicates the issue. Any attempt to quantify the effects of relational interactions leads more or less successfully to the known patterns of semantic modeling and numeric representation. And this is a strong support for the methodology

\footnotetext{
$\S$ Capital may be measured in all monetary units, including the theoretically built ones, e.g. PPS; but some economic functions such as Net Present Value (NPV) or Residual Value are also applicable.
}

of physical reasoning in the processes of quantification of interactions related to management.

Most measurable interactions of the organization with the environment are of the economic type, expressed in units of capital. Management should lead to the optimization of interactions with the environment and the stabilization of the equilibrium of the micro-macro balance in the long run. Usually, however, management leads to assumed deviations from the local equilibrium which are results of opportunity and reactions to perturbation signals derived from the surroundings, etc. Therefore, the management of interactions is a compromise between the minimax type derived from the maximization of the objective function of an organization (e.g. profit measured by EBITDA), and the minimization of the risk of the micro balance destabilization in time. A comprehensive approach to non-linear optimization tasks is an excellent source of inspiration in using physical methods of reasoning that can be adopted for management purposes.

In terms of interactions associated with management and the organization, one cannot overlook the way these interactions function. If interactions in physics can be measured by determining the final and initial state, the following question arises: can the same measurement be applied in a given management case, regarding only the initial and final state? Accepting the epistemology built on the RBV (Resource Based View) model of management [32, 33], it has been proved possible to use linear space formalism and the Debreu utility theory [30]. The same description of the resource state change can be described by a linear operator in Banach space and its set of eigenvalues independent of the way in which the process proceeded [18]. Then the length of the eigenvector becomes a measure, and the state is determined by the coordinates of the base vectors of the utility space. However, there is a serious constraint in establishing the bases of linearly independent vectors (economic categories) and the scale of measurement, preferably a relative. It is difficult to find a better reference to physical reasoning. On this basis, the paradigm of the existence of optimum management was formulated, and research program of "representative management" (in Lakatos' sense) was introduced [9].

An excellent example of the use of linear vector space methodology in management science is the multicriteria analysis [17]. Some changes in the initial set of variables allow a definition of the operator of changes. The resulting vectors allow their length calculations, and provide supporting information for decision-making. It is a crucial technique for the feasibility studies of investment.

Physics deals with the structure of material systems, which is perhaps more the domain of chemical physics and physical chemistry. However, these sciences overlap, and formal methods are derived entirely from the methods of mathematical physics. Therefore, physical reasoning in the structural studies of atoms, molecules, solids, etc., is fully rational. But can organizations be regarded 
as structures with specific topologies? In terms of RBV - yes, but not necessarily in terms of social sciences, no matter how the relational connections - the most humane aspect of the structure of the organization - behave in the topology of the network (e.g. peer). Besides, the management aspects concern not only the structure of the organization, but there are also: networking problems and structural aspects of networks, logistic problems (the problem of the shortest path), and the problems of the topology of resources that are typical minimax problems [17], free from the burden of social problems. They are also measurable, so physical reasoning has full acceptance in those cases, especially in the case of optimization and the use of minimum rules [17]. However, the most interesting relationships seem to be expected in the case of the structure of the organization and its resources. One can talk about a defined topology of resources as they are never random but subject to the rules of counting, optimum distribution and optimum utility. There are relationships between resources expressed by the circuits of documents and organizational structures, process maps, etc. Each act of management leads to changes in the state of resources (capital changes, organizational changes, functionality, etc.) with a varying degree of success. The purpose is usually to optimize but the problem of limited rationality does not always allow to achieve the optimum. And in the topological optimization of resources, one can expect interesting inspirations, derived from the analysis of chemical and physical structures. This research field is not currently exploited, and it seems to be promising for deep analogy forming.

In conclusion, some objectives and subjects of research development in time should be identified. This applies to both physics and management. Physics has developed a formal procedure of building models that quantitatively describe the time-dependent processes, and this manner of reasoning has been assumed by other natural sciences. Part of quantitative models that relate to some aspects of rational management allows the use of physical reasoning regarding the development of the system in time. The condition is to find the objective function and the development of a semantic model of the system managed in time. However, many management problems do not follow the typical quantitative models, as they relate to future events. Moreover, decisions are taken under the conditions of uncertainty, and therefore the probability of errors resulting in the future is rather large. It means that management is looking for efficient and effective models for inference in formal sciences, and one of the processes reducing the uncertainty is the objective function discontinuity in time, as well as the dependence of decision-making for the next subinterval on the results of the previous one. This area of reasoning offers wide room for common forecasting methods and research for analogy-based models.

It may be concluded that management shares some common characteristics with physics, economics and social sciences (especially psychology). However, there ex- ists an area of problems that has no equivalence in any of the sciences mentioned above. These aspects have no measure and are related to social problems such as: organization culture, intellectual capital, knowledge management, etc. What seems the most spectacular in this question is the psychoeconomic research [11], which in general rejects rationality, measurement and minimum principles in management. It is mainly founded on social processes based on beliefs, credence and feelings, usually resulting in important social and economic changes (e.g. the economic crisis caused by the speculation bubble bursting, and the ensuing catastrophic psychological reactions), which are difficult to forecast and evaluate ex-ante and are mainly derived from the bounded rationality of management decision-making. In this case, physical reasoning is pointless, but it can offer some interesting metaphors (the chaos, complexity and catastrophe theories) widely applied in social sciences with more or less sense [20]. But if for any phenomenon a suitable measure is to be defined, then such a problem may be included in the field that is common with physics - that of reasoning and form accepted by physical methodology.

\section{Selected aspects of management that are interesting for a physicist}

The following aspects of management science, for which it is rational to seek analogies, are derived from physics and natural sciences:

1. Description of the organization and its structure (topology and functionality), associated with a macro description of a management entity related to an external observer, or a micro description from the standpoint of an internal observer, analogous to the construction of networks of interacting bodies with a specific topology. Possible macroscopic and microscopic descriptions claim that metaphorical reasoning area. However, there are instances of managed processes where that metaphoric area may be replaced to the inference by analogy (the higher status of common relations). One of the most important examples is the management of information transmission using the criterion of the shortest path. Another good example is the logistic problem [17]. Seeking a numerical representation of a non-mathematical problem is an example of reasoning transferred from natural sciences. A particularly important aspect of the description of the organization is the Resource Based View (RBV) approach [32], where the organization may be described in a formal mode as follows [9]:

Let there be a given composite entity (structure) $S=$ $[U, O, R]$ determined on economic objects $U$, called an organization, consisting of:

1. non-empty set $U$ of objects called Resource $S$,

2. indexed set $O$ of operations allowed on set $U$,

3. non-empty, indexed set $R$ of possible relations on set $U$. 
Then set $S$ is an economic organization in the resource approach with the defined state of resources at a given moment.

Using the above definition, management can be defined as an action to any change of the state of the set resources $U$ in time, within the operations and relationships permissible on set $S$. If operating on elements that are isomorphic representations of the defined objects, relations or operations of structure $S$, some true observation sentences are derived, then the isomorphic set is a model of organization $S$.

This is typical physical reasoning applied to social sciences. The sum of resources with specific activities and relationships forms a formal representation of the organization and allows to introduce its syntactic homeomorphisms expressed in a computer language. A psychological problem for many researchers of the humanistic trend is the issue of the reification of this reasoning. But this is the only method leading to numerical algorithms, and the RBV approach is one of the most spectacular successes of management science $[32,33]$.

2. Decision-making under the conditions of uncertainty and the use of fuzzy logic. While in physics the estimation of measurement error is possible on the basis of many repetitions of an experiment or matching results with the formal model to determine deviations, the exact estimation of uncertainty in management decisions (experiment) is not possible with high probability. The process of investment decisionmaking carries a risk that the manager must estimate quite precisely. In this regard, the linear programming approach is the most widely used support of quantitative estimations [17]. Inference on this basis is a good analogy with the methods of linear algebra in physics, in particular the transformation of linear operators in unitary spaces [15]. An important element in distinguishing the management of an organization and supervising the physical process is the ability to make decisions regardless of the rationality and optimization aspects [26]. While in the physical process the principles of minimum energy, minimum path, minimum time and minimum act are the basic laws for a researcher trying to conduct an experiment and discourse, in management the subjective factor allows even serious deviations from the rules to the corresponding real-life processes. Thus, scientific discourse does not cover the relations between social and natural sciences. But it seems logical that the temptation to use the principles of minimum action and maximum effectiveness in the description of economic and social interactions of the organization with the surroundings justifies even some abuse in the absence of any conditions of applicability of the analogy $[35,36]$. This applies in particular to the definition of metrics and categories that make up the objective function or the global index, such as usability, functionality or usefulness. In this case, using the experience of physics is fully justified.

Another important question in decisionmaking is related to the threshold level of switching between the choices of options. In physics, switching between steering values is subject to Boolean logic, due to the deterministic description of a state. In management practice, the use of sharp thresholds of switching is rather rare. Decisions based on fuzzy logic thresholds seem the most appropriate. It is observed in the neural network approach supporting decision processes [49].

3. Business processes and their description (linear and nonlinear). At this point, the analogies between natural sciences and management seem to be the most accurate and reasonable $[35,36]$. Assuming that interactions of matter by electrostatic, magnetic and gravity forces are well-described by theoretical physics, it seems to be natural to transfer the suitable descriptions in the form of metaphors or analogies for management purposes. However, an organization representing a management entity may interact with the environment or other organizations in a different way from material objects. Also to be taken into account are the interpersonal relationships, the impact of intergroup context and variability of the environment (e.g. the collapse of the resource set as a result of technological revolution, or lack of interest in a product). The most important problem, however, is to describe the state of the managed entity. What is the state of the organization at any given time? It can be assumed that the set of resources, their value and capacity expressed in the form of a balance description of the organization may be a good initial approximation. But what shall we do with the context, which may change the usefulness of organizational resources in a short time, even in a catastrophic manner? The thermodynamic model of the state description with a few macroscopic parameters appears to be the perfect analogy for economic processes [32]. Physical reasoning leads to the conclusion that any change of the state of resources in time, expressed as a difference in values, is a good description. If the change does not depend on the way but the initial and final values of the state, it is useful in describing management processes [18]. Some successful descriptions offered by Econophysics demonstrate reasonable analogies [37, 38]. But the most interesting approach is the description of management through some changes in the utility of resources. Ever since Debreu, utility has been the basis of the theory of generalized value. The application of vector space formalism to utility has been very successful [40]. Defining utility by a set of parameters representing categories allows not only the use of the metric vector space methods, but also takes into account the subjective assessment of the components of the vector of utility. The renormalization to $100 \%$ can offer a good scale for comparisons. The length of a vector of resources utility varies from 0 to 1 . In this way, physical reasoning defines the method of measuring any changes of the utility vector components and their importance, regardless of the level of subjective assessment, and the instantaneous impact of the environment. In a normalized space, the measure of the usefulness vector is invariant to its surroundings and time. But there is another question: is 
it possible to decompose the analyzed process into a linearly independent sum of canonical processes, as it takes place in physics? In management, it may be concluded that the total number of decisions in various processes results in global changes in the organization. However, in the case of strategic management it is not possible to create a priori a Cartesian set of decision processes because a strategy cannot be decomposed into separate substrategies. A strategy is a multiple-choice option construction realizing as a set of consecutive decisions [1], depending on each other. Therefore, reasoning taken from natural sciences can help optimize strategies formulation based on the Bellman theorem. Another important example is the use of the Brownian motion theory for management processes with stochastic properties, such as risk management, portfolio definition, etc. [41]. The stochastic description of problems with the Wiener property uses the famous Monte Carlo method [42] and polynomial simulations. It should be noted, however, that the main condition of its applicability is the existence of an acceptable semantic model (a well-established analogy).

4. Forecasting and planning (strategy). It is a very important part of managing the organization or an economic process. It requires decisionmaking under the conditions of uncertainty based on some internal and external data. The most characteristic feature of physical reasoning in this case is the description of consequences of consecutive decisions and the Markov property of the formed strategies along time [1]. The most appropriate analogies may derive from chemistry: polymerization reactions as a stochastic process leading to similar but different products, and the radioactive decay explaining the kinetics of the first-order processes. For strategy formulation, the shorter interval for optional decisions, the better prognoses are possible in subsequent subintervals. Similarities between applied methods in physics and management should be found primarily in the problems related to the applicability of the binomial distribution, in particular some concepts of quantization with the binomial trees method related to options, portfolio management [43] and risk management using optional scenarios [44].

\section{Typical quantitative methods of management}

Management uses a wide range of evaluation methods supporting the quantitative description of problems [17], mainly related to the quantitative support of decisionmaking under the conditions of uncertainty and optimization processes. They mainly represent the domain of management science called operational research [24], which remains in analogy with the mathematical methods of physics. The close relations between counting methods and models used in both cases may be discussed. Some examples include:

1. Linear programming used in the evaluation procedures of investment projects. One may find it analogous to the isoparametric problem with constraints, well known from mechanics [45]. In management, an interesting algorithm called the simplex method is widely used. It allows a simplified solution to the system of linear equations with constraints [17]. In feasibility studies, acceptable solutions to any real problems are always restricted to positive values (labour, capital, the amount of resources, etc.) and defined by real numbers, which distinguishes them from constraints in physics, where negative values are not prohibited, and even in quantum mechanics, where the vector space of complex numbers may be used [45]. Searching for deeper analogies in relation to linear space formalism seems to be very interesting.

2. The game theory is one of the most important methods of describing interactions between the managed entity, the surroundings and economic micro and micro-macro equilibrium [18]. Similarly to physics, the game theory allows an analysis of the balance state strategies and trajectories, e.g. pursuit-evasion games in metric spaces [46]. But this method is far more important in social science. Despite the von Neumann theorem and its applications used without fulfilling the conditions of its use, it is always a source of valuable metaphors. Adapted from physics, the methods of minimax determinations are valuable analogies for quantitative aspects of management. The newsboy problem is one of the best examples [50].

3. Optimization methods, in particular the variational methods and the algorithm of consecutive approximations (adaptive management) [47], commonly used in physics, are important in operations research [17]. The analogy between physical reasoning and operations research methods is very close, and the solutions reached, like the above-mentioned newsboy problem with discontinuous or continuous payoff function [24], logistic problems or similar tasks, are experimentally validated. There are no examples of the use of perturbation accounting in the minimax approach to management, but one can expect that in the study of economic interactions with the use of the RBV model and a given analytical objective function, the perturbation theory may be applied for the reduction of ceteris paribus influence.

4. Statistical methods are the basis of quantitative management problems analysis of the non-deterministic type [17]. Statistical physics may be a source of scientific inspirations and can offer valuable research methods for social sciences, particularly for economics and management. Taking into account the specific similarities between the description of physical phenomena and the economic ones, econophysics should be recognized as the most successful venture in the analysis of the stochastic behaviour of stock indices, income distribution, etc. [39]. The analysis of the optimum portfolio or statistical distribution of assets (e.g. the Black-Sholes formula, or the method of binomial trees) are the foundations of the methodology of risk management [43]. Also, the one-dimensional Ising model of ferromagnetism in economy has been used with success [30] and still appears interesting $[51,52]$. As far as the probabilistic methods are concerned, the analysis of processes with the Markov property should be distinguished. In strategic management, 
it is the basis of the real options approach [1]. However, in many cases social sciences abuse the stochastic methods without justifying their applicability, e.g. the chaos theory, turbulence, etc. [20]. Some researchers are convinced about not only their metaphoric sense, but also a deep level of their analogical properties without giving any statements to support these hypotheses. This area of quantitative methods and models derived from physics, relating to interactions and simulations of achieved results, can be successful in management science.

5. Network analysis and fuzzy logic used in decisionmaking [24] are important parts of management science, where similarities to strictly physical inferences are very well conditioned. Also, the creation of numerical representations of decision problems is a scope of neural network and the Bayesian logic approach. In this case, computerization standardizes the method of setting ranges, thresholds and switching functions (or systems of equations) describing the control processes [18]. The lower the level of management (e.g. operational control of the production process), the more decision-making models are acceptable. In the case of strategic management, an analogy to hardcore sciences may be used occasionally, because the decisions taken are in general not subjected to measuring procedures and remain axiological evaluations in the multicriteria analysis sense [17]. Although everyone making decisions would like to get some quantitative support for his extrapolation of the results of uncertain decision related to the future, seeking analogy sets model parameters for decision-making at the higher level of meta-analysis, and logical fuzziness based on patterns of information is observed.

\section{Some current problems connected with the analogies}

1. Resource Based View of an organization. It is the model of organizational description that is the closest to the formal physical systems description. It treats organizational resources as measurable objectives grouped in a given structure with a defined topology, possible internal relations and defined interactions with the surroundings. In this way, there exists a set of macroscopic parameters allowing an average description of the objective function regarding some changes of the resource set. It is also possible to define the state of the resource set at a given moment of time. What is more, assuming resources as objects of the utility vector space, all benefits of vector space formalism are available for the description of the transformation of the resource set in time. As a result, linear operator formalism from quantum mechanics can be a very useful analogy for the study of changes in management. It is a powerful tool in the utility theory, the theory of value and the theory of measurement in management.

2. Strategic planning and forecasting. The 2008 2009 financial crisis introduced a faux pas in the existing quantitative models of strategy building and forecasting. Management is waiting for new models that would be more accurate and easier to estimate. Too drastic simplifications of the reality, as well as the wide postponing influence of the existing ceteris paribus in analytical models of econometry, make it impossible to estimate with any satisfying accuracy the uncertainty of any forecast. No deterministic models exist, and all the probabilistic approaches should evaluate the suitable level of accuracy. There is still an open area left for the adoption of estimation methods derived from statistical physics. If one assumes that a given model of differential equation resolved with a subtractive method offers results evaluated with deficiency, whereas resolved with an integral method (e.g. Green's function method) [45] offers the same solution evaluated excessively, then the right solution is included in an estimable strip. The acceptance of such reasoning in time-dependent management questions may result in some interesting effects, taking into account the fact that for right decision-making, the exact number is not necessary, but rather a precise evaluation of uncertainty offers the crucial supporting information. In terms of physical reasoning, it is an interesting research area.

3. Models, numeric representations and computer-aided decision-making.

Before supporting any decision processes by means of computers, or receiving necessary data for further meta-analyses, it is necessary to find a suitable semantic model and its numeric representation. Since the majority of management aspects are non-mathematical problems, the difficulty of formal description, introduction of measure and elimination of subjective influence has arisen. Furthermore, the problem of the acceptable Cartesian division of a complex problem and ceteris paribus estimations are necessary to resolve. Physical reasoning allows to formulate five important conclusions:

(a) Modeling should be designed from an external observer's point of view,

(b) Find as much acceptable Cartesian cross-sections of a given problem as possible,

(c) Define a measure for a given aspect or explain its non-measurable character,

(d) Find a possibility to use the minimum, maximum or minimax principle,

(e) Explain the rationality and a level of uncertainty (ceteris paribus estimation).

The application of the above principles of modelling results in a consistent set of management paradigms, leading to measurable logical separations of problems for which there are always numerical representations and as a consequence - a corresponding set of syntactic representations. The IT support is crucial at the operational level of management. The higher the level of management, the less important the syntactic information becomes. There are examples of choice and switching in non-mathematical problems solved with neural networks 
without precise syntactic solutions $[53,54]$. However, in those cases the semantic model and its measure must be defined.

4. Nonlinear problems of management and optimization. These management issues are related primarily to the decision-making analysis, where the objective function cannot be expressed by means of linear dependence or linear combination of independent variables (a system of linear equations). These are mainly issues related to optimization, feasibility area, optimal portfolio, sensitivity and multicriteria analysis. Nonlinear problems may also include conflict situations, for which the right solution is obtained from the game theory methods. More aspects of this section were discussed earlier.

5. Axiological evaluation of management. Any act of governance is assessed in terms of the good, evil, rationality, justice, etc. It is necessary to define the measure and measurement methods allowing the categorization of the results. Such methods are often based on the comparison with a model determining the point scale, finding a switching level, etc. When introducing the analogy with a physical experiment to evaluate the management problem axiologically, it is necessary to set a level of rationality and objectivity of the selection, which usually is neither simple nor clear. That is why the support of the methods of philosophy of science at this point is of particular importance.

6. Quantification, measurement, rationality Is accurate information necessary for making a proper managerial decision? Generally - not. Is accurate information necessary for making the right hypothesis related to the experiment in physics? Generally — yes. This is the field of the greatest discrepancy between physical reasoning and inference in management science. Does it mean that the method of quantification and measurement taken from physics is not applicable in management? No, simply because there are no better methods. The main problems lie in the rationality of categorization, the choice of scale and the acceptable description method (e.g. vector space formalism). In management, quantification is severely limited in use, Simon's theory of bounded rationality is universally recognized $[11,18,26]$ and so it is crucial to demonstrate that an increase in the level of subjectivity and rationality constraints does not affect the scale or definition of measure. It has been proved that the limitation of rationality in issues for which measure is defined as a length of utility vector changes only coefficients of linear combination, but does not alter the definition of the measure (it is still the length of the vector) $[13,18]$. Subjectivism changes the significance of categories of general utility, but still applies to the measurement definition in any isomorphic vector space. It is a nice analogy to physical reasoning.

\section{Conclusions}

Which methodological area of physics may be shared with management science? The aspects listed below seem the most promising:
(1) The description of a system of objects (e.g. a multi-body system of interacting bodies). Inspirations derived from this area allow a mechanistic, thermodynamic and stochastic approach to social science systems (as it is done in econophysics).

(2) The mechanistic approach defines the state of a system in space, introducing the internal and external observer, and allows an estimation of a trajectory. The most important inspiration here is the movement in the central forces field and mechanical definition of force, energy and potential, enabling the inference of changes in time. The RBV model largely stems from the fundamental principles of description of physical bodies, their measurable properties and interactions.

(3) Thermodynamics allows a valuable inspiration of the micro state definition by a system of macro parameters. In addition to this, strict formalism of classical thermodynamics is particularly suitable for defining the function of state and its time dependence. The ideal gas model is an inspiration for the description of economic interactions of micro systems at the macro level. Some successful analogies in the econophysics domain may be demonstrated.

(4) The stochastic approach is a very useful tool for forecasting the behaviour of economic systems. Description methods based on the Brownian motion, moving average, variable auto regression are used for supporting decisionmaking. The Monte Carlo method, well-known in physics, is a fundamental tool in risk analysis and optimum portfolio calculations. The stochastic methods derived from physics are crucial in management.

However, the most useful contribution to the management of physical reasoning would be the introduction of a widely accepted definition of the managed system from the perspective of an external and internal observer, and the state of the system at a given moment of time. This would change the description of a system state as a function of state, equation of state, or linear operator. Unfortunately, the majority of management objectives do not have any abstract representation, allowing the introduction of an acceptable definition of the system. Hence the need to create an analogy to natural sciences, enabling the construction of semantic models for which a symbolic representation always exists.

The main consequence of physical reasoning in the management science is a new epistemology in terms of the physicalistic approach, which might provide a uniform point of view. It gives a clear picture of the selective demarcation based on the existence of a measure. This view must be confronted with the epistemologies derived from the standpoint of sociology and social sciences, psychology and economics with econometrics and operation research. Some common paradigms and universal statements may be found at the cross-section 
of all the views, and clear epistemological foundations of the order may be fixed. The presented epistemology is a concept of the development of management science, where measurable problems are supported by behavioural aspects and described by optimum mathematical formalisms. The physicalistic approach eliminates very questionable metaphoric paradoxes encountered in the problems of strategy descriptions, which are simply an ill-posed problem, not only from the perspective of scientific methodology, but also the logic of scientific discovery. Hence the ordering universalism of the physical approach of any interdisciplinary set of issues, using the rules of formal logic and measurement theory.

\section{References}

[1] K. Obłój, Strategia organizacji [Strategy of organization], Polskie Wydawnictwo Ekonomiczne, Warszawa 2007.

[2] Elastyczność organizacji [Elasticity of organization] Ed. R. Krupski, Wydawnictwo Uniwersytetu Ekonomicznego we Wrocławiu, Wrocław, 2008.

[3] B. de Wit, R. Meyer, Strategy Synthesis: Resolving Strategy Paradoxes to Create Competitive Advantage, Thompson Learning, London, 2005.

[4] Ł. Sułkowski, Epistemologia w naukach o zarzadzaniu [Epistemology in Management Science], Polskie Wydawnictwo Ekonomiczne, Warszawa, 2005.

[5] P. Johnson, J. Duberley, Understanding Management Research: An Introduction to Epistemology, Sage, London 2000.

[6] O. Nodoushani, Systemic Practice and Action Res. 12, 557 (1999).

[7] D. Melé, Journal of Business Ethics 44, 77 (2003).

[8] C. Mesjasz, www.zis.agh.edu.pl/sociophysics/ pdf/sociophysics_20071213.pdf ["Physics and Social Science - Some Problems for Explanation"].

[9] T. Gospodarek, Int. J. of Economics and Business Research 1, 409 (2008).

[10] T. Gospodarek, Organizacja i kierowanie 4, 7 (2008).

[11] C. Camerer, G. Loewenstein, in Advances in Behavioral Economics, Eds. C. Camerer, G. Loewenstein, M. Rabin, University Press Princeton, Princeton, 2003.

[12] G. Stigler, Essays in the History of Economics, University of Chicago Press, Chicago, 2005, Chap. 5.

[13] T. Gospodarek, in Information Management, Eds. B.F. Kubiak, A. Korowicki, Gdańsk University Press, Gdansk 2009, p 76.

[14] T. Gospodarek, Management 11, 39 (2007).

[15] I.M. Gelfand, Lectures on Linear Algebra, Dover Publications Inc., New York, 1961.

[16] P.D. Strafin, Game Theory and Strategy, The Mathematical Association of America, Washington D.C. 2002.

[17] D.R. Anderson, D.J. Sweeney, T.A. Williams, An Introduction to Management Science. Quantitative Approaches to Decision Making, 12th Edition, West Publishing Company, St. Paul, 2008.
[18] T. Gospodarek, Modelowanie wybranych zagadnień nauk o zarzadzaniu oparte na metodzie naukowych programów badawczych $i$ formalizmie reprezentatywnym [Modeling in Management Science Based on Research Programs and Representative Formalism], Wydawnictwo Uniwersytetu Ekonomicznego we Wrocławiu, Wrocław 2009.

[19] C. Mesjasz, International Relations, Cybernetics and Systems. An International Journal (Vienna) 25, 763 (1994).

[20] A. Sokal, J. Brickmont, Fashionable Nonsense. Postmodern Intellectuals' Abuse of Sciences, 1998, Polish edition: Modne bzdury. O nadużywaniu pojęć z zakresu nauk ścisłych przez postmodernistycznych intelektualistów, Prószyński i Spółka, Warszawa 2004.

[21] T. Copeland, V. Antikarov, Real Options: A Practitioner Guide, Texere, London 2001.

[22] R.E. Bellman, Dynamic Programming, Princeton University Press, Princeton, New Jersey 1957.

[23] B. Flyvbjerg, Making Social Science Matter: Why Social Inquiry Fails and How it Can Succeed Again, Cambridge University Press, Oxford 2001.

[24] D. Stoljar, in The Stanford Encyclopedia of Philosophy (Fall 2009 Edition), Ed. N. Zalta, http://plato.stanford.edu/archives/fall2009/ entries/physicalism .

[25] Badania operacyjne [Operation Research], Ed. W. Sikora, Polskie Wydawnictwo Ekonomiczne, Warszawa 2008

[26] H.A. Simon, Administrative Behavior, The Free Press, New York 1976.

[27] J.B. Copeland, in The Stanford Encyclopedia of Philosophy (Fall 2008 Edition), Ed. E.N. Zalta, http://plato.stanford.edu/archives/fall2008/ entries/church-turing .

[28] S.S. Stevens, On the theory of scales of measurement Science 103, 677 (1946).

[29] G. Debreu, Theory of Value. An Axiomatic Analysis of Economic Equilibrium, Wiley, New York 1959.

[30] K. Huang, Statistical Mechanics, Wiley, New York 1963, Polish Ed. PWN, Warszawa, 1978.

[31] B.W. Arthur, in The Complexity Vision and the Teaching of Economics, Ed. D. Colander, Edward Elgar Publishing, Northampton, 2000, Chap. 3.

[32] J.B. Barney, Journal of Management 17, 99 (1981).

[33] http://www.fsc.yorku.ca/york/istheory/wiki/ index.php/Resource-based_view_of_the_firm .

[34] O. Truijens, Sprouts Working Papers on Information Systems 3 Article 6 (2003), http://sprouts.aisnet.org/3-6/.

[35] P. Mirowski, More Heat than Light - Economics as Social Physics, Physics as Nature's Economics, Cambridge University Press, Cambridge 1989.

[36] N. Georgescu-Roegen, Energy and Economic Myths: Institutional and Analytical Economic Essays, Pergamon Press, New York 1976.

[37] U. Schulze, ZEF - Discussion Papers On Development Policy 23, Center for Development Research, Bonn 2000.

[38] R.N. Mantegna, H.E. Stanley, An Introduction to Econophysics: Correlations and Complexity in Finance, Cambridge University Press, Cambridge 1999. 
[39] B.K. Chakrabarti, A. Chakraborti, A. Chatterjee, Econophysics and Sociophysics: Trends and Perspectives, Wiley-VCH, Berlin 2006.

[40] K.J. Arrow, G. Debreu, Econometrica 22, 265 (1954).

[41] I. Karatzas, Brownian Motion and Stochastic Calculus, Springer, New York 1991.

[42] N. Metropolis, S. Ulam, Journal of the American Statistical Association 44, 335 (1949).

[43] M. Jackson, M. Staunton, Advanced Modelling in Finance using Excel and VBA, Wiley 2001, Polish Ed. [Zaawansowane modele finansowe $z$ wykorzystaniem Excela $i$ VBA, Wydawnictwo Helion, Gliwice 2004].

[44] J. Hull, Introduction to Futures and Options Markets, Prentice Hall Inc., 1994, Polish Ed. [Kontrakty terminowe $i$ opcje. Wprowadzenie], WIG-Press, Warszawa 1999.

[45] F.W. Byron, R.W. Fuller, Mathematics of Classic and Quantum Physics, Addison-Wesley Publishing Company, Inc. Reading 1972, Polish Ed. [Matematyka $w$ fizyce klasycznej $i$ kwantowej], PWN, Warszawa 1973.

[46] J. Hespanha, J. Kim, S. Sastry, Proc. 38th IEEE Conf. Decision and Control 3, 2432 (1999).
[47] J. Highsmith, APM Agile Project Management. Jak tworzyć innowacyjne produkty, Polish Ed. Mikom Warszawa 2005.

[48] R. Bellman, Adaptative Control Processes: a guided tour, Princeton University Press, Oxford University Press, London 1961.

[49] H. Koivisto, A Practical Approach to Model Based Neural Network Control, Tampere University of Technology, Tampere, Finland, 1995.

[50] S.A. Lippman, K.F. McCardle, Operations Research 45, 54 (1997)

[51] W.-X. Zhou, D. Sornette, The European Physical Journal B - Condensed Matter and Complex Systems 55, 175 (2007).

[52] D. Stauffer, American Journal of Physics 76, 470 (2008).

[53] B.A. Jain, B.N. Nag, Journal of Management Information Systems 14, 201 (1997).

[54] C.-T. Lin, C.S.G. Lee, IEEE Trans. Computer 40, $1320(1991)$ 